\title{
Social support as a neglected e-learning motivator affecting trainee's decisions of continuous intentions of usage
}

\author{
Cathy Weng and Chin-Chung Tsai \\ National Taiwan University of Science \&Technology, Taiwan
}

\author{
Apollo Weng \\ China University of Technology, Taiwan
}

\begin{abstract}
Drawing from the social influence theory and acknowledging that the others' support within the work context affects employees' learning, values, and behaviours, an alternative framework was proposed to explain employees' learning satisfaction and future intention to participate in e-training programs in the current study. 578 survey data collected from employees of various corporations in Taiwan provide empirical support for our extended model. The results suggest that social support from peers and supervisors, a usually neglected factor, has significant effect on trainees' learning satisfaction, while family support, an often neglected antecedent of e-learning choice, was surprisingly found to affect trainees' continuous intentions to participate. Finally, the paper concludes with the importance of employees' perceptions of social support in terms of organisational training. The impact of human resource management policies is also discussed.
\end{abstract}

\section{Introduction}

With the presence of highly competitive markets, corporate training has become increasingly important as human capital and knowledge, while employees' skills have become competitive assets and tools for organisations (Zakaria, 2000). According to Miller (2012), the American Society for Training and Development (ASTD) estimated that U.S. organisations spent nearly US\$156.2 billion on employee training and development in 2011, and the spending has been constantly increasing over the years. Organisations have invested heavily in the training of employees, since they view training as an integral part of the strategic planning process of the firm to survive and compete in today's fast-paced, changing world (Chen, Sok, \& Sok, 2007). Human resource managers have, as a result, placed a high priority on finding the most effective and efficient ways to train people in organisations today.

Technology and Internet advancements have changed our learning environment in organisational settings during the past decade. Numerous companies worldwide have adopted e-learning solutions to offer learning-on-demand opportunities to employees in order to reduce training costs and time, while improving their productivity (Kranz, 2008). In general, e-learning refers to all types of teaching methods via electronic media, including the Internet, intranets and extranets, satellite broadcasts, audio/video, interactive TV and CD-ROMs (Chang \& Tung, 2008); however, in this study, e-learning is defined in a narrower term as the use of interactive networks and advanced computer technologies to create, foster, deliver, and facilitate learning anytime and anywhere. This is more appropriate as there are new forms of e-learning solutions nowadays. According to Miller (2012), in the U.S. corporate training market, corporations are investing a substantial amount of money in this new form of training, and about $37.3 \%$ of all learning hours are used by employees to pursue development through some form of e-learning technique. ASTD suggests that the e-learning method of training has moved into the mainstream (Kranz, 2008). Thus, with the continuous development of this new education paradigm, we can no longer underestimate the important role it plays in training employees for organisations to increase or sustain their comparative advantage in human capital.

The rapid growth of e-learning in organisations has resulted from the promises it gives to businesses. The great advantages of e-learning have been widely discussed and documented by researchers and practitioners all over the world, such as the ability to learn from the employee's desktop, the convenience of learning from home, the savings on traveling costs, allowing companies to have globally trained staff, the reduced overall training costs, the rapid dissemination and revision of training materials, the shortened training period, and the enhanced opportunities for active learning (Chen, 2008). Even though there is such a great demand for e-learning from businesses, failures do occur (Sun, Tsai, Finger, Chen, \& Yeh, 2008; Wang, Ran, Liao, \& Yang, 2010), but little is known about why. Some information technology 
research has shown that the success of any form of e-learning solution in an organisation depends highly on user satisfaction and other determinants that will eventually lead to users' continuous intentions of usage (Sun et al., 2008). In order to prevent underutilisation of the technology's capabilities and waste of huge human resource investments, researchers and practitioners should focus on finding effective strategies to enhance user satisfaction as well as continuous intentions of usage or participation.

In the past, much research has provided various theoretical frameworks for studies on user technology acceptance. Among them, the technology acceptance model (TAM) is one of the most widely used models to overcome the problem of underutilised systems, in part because of its robustness and simplicity. The TAM was developed by Davis (1989), building on the theory of reasoned action (TRA), which is a psychological theory concerned with determinants of consciously intended behaviours. The TRA posits that an individual's beliefs influence his/her attitude (a personal factor) and subjective norms (a social influence factor), which in turn leads to intentions and then behaviours. Disregarding the social context, the TAM further identified two important beliefs as primary predictors - perceived ease of use perceived usefulness of the adoption behaviour. It alleges that these two factors are the basis for attitudes towards adopting a technological innovation, which then determines the intention to use, and at last leads to the actual behaviour of usage (Davis, 1989).

Even though the TAM has received extensive empirical support through validations, applications, and replications, many researchers have questioned whether it underscores the role of social influences in the social context under the adoption and utilisation of information systems (Chuo, Tsai, Lan, \& Tsai, 2011). In addition, studies have also found evidence that acceptance and continuous usage behaviours are determined by different factors, suggesting that further research about information technology continuous usage needs to take this into consideration (Hsu, Yen, Chiu, \& Chang, 2006). Acknowledging that the existing variables of the TAM cannot fully reflect a user's continuous motives, and in the hope of generating a better understanding of the adoption of technologies, researchers have suggested the need for the TAM to incorporate additional factors or integrate with other models and theories to improve its specificity and explanatory utility (Lu, Yu, Liu, \& Yao, 2003; Ong, Lai, \& Wang, 2004). In the current context, it is vital to note that an employee's participation in e-learning on the job is not an individual phenomenon, but rather we need to consider influences beyond the individual user level, affecting how he/she adapts to the new learning environment. Such influences may exist anywhere around the user's social environment. Levitt and March (1988) suggested that the broader ecologies of learning that shape learners' behaviour should be included in the analysis, and urged researchers to consider contextual factors that influence how employees use resources to perform tasks.

Even though numerous extended TAM studies did include the impact of subjective norms as a form of social influence on decisions of technology adoption in a wide variety of contexts (Schepers \& Wetzels, 2007; Raaij \& Schepers, 2008), it was excluded in the current study and was replaced with a normally neglected variable, social support. Subjective norm is a person's perception of whether most people who are important to him/her think the behaviour in question should or should not perform (Fishbein \& Ajzen, 1975), and it reflects the perceived social pressure that individuals may have on the decision to comply with their important referents. Despite the fact that prior research did find significant effects of subjective norms on adoption behaviours, inconsistent empirical results were found (Mathieson, 1991; Davis et al., 1989). Discussed by Venkatesh and Davis (2000), the compliance effect might occur only in mandatory situations but not in a voluntary setting. Under the current study, corporate employees usually have a choice of the types of professional trainings they participate in or attend, so it would be more likely to be in a voluntary context; as a result, the effect of subjective norms on their decisions is less likely to be significant. Moreover, as suggested by Courneya and McAuley (1995), the construct of social support could be another type of social influence, which is distinct from subjective norms to be included in the analysis applying the theory of planned behavior. It is also a more consistent variable correlated to the behavioral outcomes (Ball, Jeffery, Abbott, McNaughton, \& Crawford, 2010); therefore, social support is applied as a determinant of the intention in the conceptual model we built.

In the present study, social support was considered as an important variable representing the social influences upon employees. Social support comprises the exchange of resources between at least two individuals, with an intention of enhancing the well-being of the recipient (Shumaker \& Brownell, 1984). It can involve providing empathy, care, love and trust, and actual aid in time, money, advice, information 
and suggestions (House, 1981). Here, social support has been defined as helpful social interactions on the job from supervisors, co-workers, or family (Chuo et al., 2011; Felman-Baruch \& Schwartz, 2002; Way \& MacNeil, 2006). Numerous studies have found proof that social support is positively associated with staff well-being (Chuo et al., 2011; van Veldhoven, de Jonge, Broersen, Kompier, \& Meijman, 2002), and improves job satisfaction (Felman-Baruch \& Schwartz, 2002; Way \& MacNeil, 2006). Thus, aiming to advance the information systems' literature concerning the effects of social influences on technology adoption, social support from different sources perceived by the employees was added in the current study to explore the possible role it plays in determining learner satisfaction and decisions as to whether to participate in the organisation's e-learning programs in the future.

Satisfaction, one of the most important concepts in marketing, has also attracted much attention in consumer research, for many have proved its vital role in consumers' repurchase decisions (Anderson \& Sullivan, 1993). In view of this, Bhattacherjee (2001) built a TAM integrated model to explain that users’ intentions to continue using a particular technology are driven by their satisfaction with prior usage. Many other studies on information technology and information systems have also found empirical support for this causal relationship, and have demonstrated that customers with higher levels of satisfaction with a service or product will have higher subsequent use (Chiu, Sun, Sun, \& Ju, 2007; Hsu et al., 2006; Roca, Chiu, \& Martinez, 2006). Thus, building upon this line of argument, the satisfaction of e-learners in corporations was also added to our extended model in the study as an outcome variable as well as the mediator for attitudinal variables in the intention of continuous usage.

Self-efficacy is an individual's confidence in his/her own ability to execute an action necessary to accomplish a given task or activity (Bandura, 1986). It is thought to play a key role in determining what activities an individual engages in, how much effort is put into pursuing that task, and how persistent the individual is in the face of obstacles, so it is not only a belief in ability level, but it also drives the motivation necessary to conduct the behaviour. Emerging from motivation studies, self-efficacy, therefore, is recognised as an essential variable in enhancing individual performance and in having critical effects on the various types of learning outcomes (Bandura, 1986). Since self-efficacy is domain specific (Joo, Bong, \& Choi, 2000), the concept of e-learning self-efficacy (ELSE) is introduced, referring to the belief that one can be successful in e-learning activities. Recent studies also indicate that an e-learner's computer self-efficacy directly affects his/her perceived e-learning satisfaction and behavioural intentions to continually use the online learning systems (Chang \& Tung, 2008; Hsu et al., 2012; Sun et al., 2008).

To further enhance the model for e-training solution continuous use, the TAM was modified in an important and unique way here. The present study combines the TAM, social support theory and user satisfaction theory, and adds one additional variable, e-learning self-efficacy, to propose a new hybrid TAM to study employees' continuous behavioural intentions to use e-training solutions in organisations. This study also aims to uncover the important determinants affecting the continuous intentions for employees. With an understanding of the antecedents of adoption based on employees' perspectives, organisations might better deploy and manage their resources when they attempt to develop and deliver online training and encourage their members to participate.

\section{The theoretical model and hypotheses}

In this section, the theoretical model based on previous research and related literature proposed in the current study is depicted in Figure 1. Then, the hypotheses of the study are listed below. 


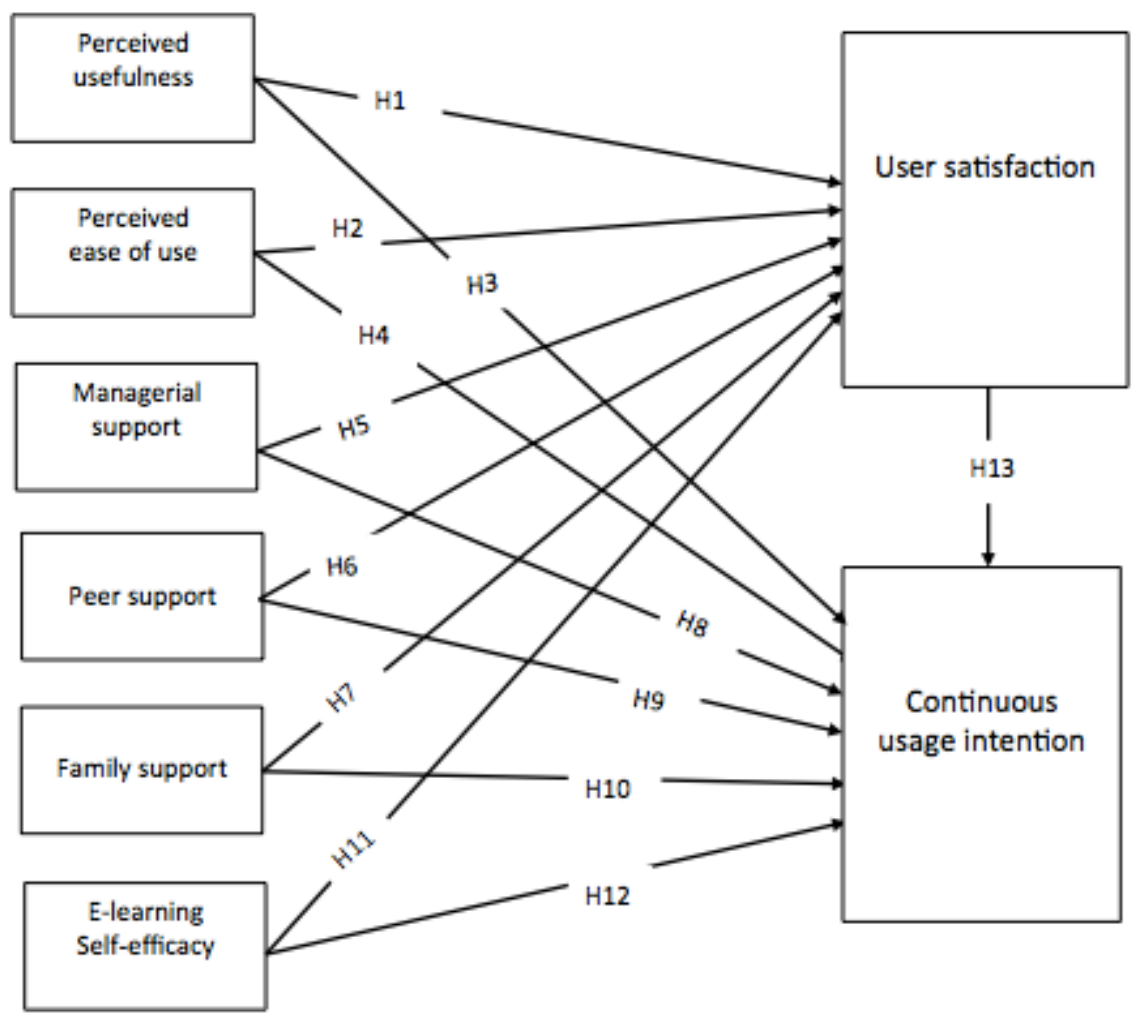

Figure 1. The theoretical model

\section{The TAM}

Because of the predictive validity and strong empirical support of the TAM, like other studies of user acceptance for technology, the present study also used the TAM as the starting point for the development of a new model to explain employees' continuous intentions to adopt e-training in corporations. As mentioned, Davis (1989) first introduced the TAM as a theoretical extension of the TRA in an attempt to understand why people accept or reject information technologies. The original TAM explained the causal relationships between beliefs, users' attitudes, intentions, and actual technology adoption behaviour. It predicts user acceptance starting from two particular beliefs: perceived usefulness and perceived ease of use.

Several studies on finding drivers of a successful e-learning outcome have suggested that the TAM is appropriate for predicting learning satisfaction in e-learning and have shown that the constructs in the TAM (such as perceived usefulness) significantly affect learner satisfaction (Arbaugh, 2000; Sun, et al., 2008). As Arbaugh (2000) described in his study on the acceptance of web-based MBA courses, perceived usefulness and perceived ease of use of the delivery medium will influence students' attitudes towards their learning experience, enhance the experience and satisfaction with the experience, and, therefore, make them more likely to participate in other e-learning opportunities. Thus, the following hypotheses were derived:

H1: The perceived usefulness of an e-learning system is positively related to the e-learners' satisfaction with the e-learning.

H2: The perceived ease of use is of an e-learning system is positively related to the e-learners' satisfaction with the e-learning.

Since some studies have found a doubtful mediating role of attitude in the TAM, many follow-up studies have also tried to simplify the TAM by finding direct relationships between perceived usefulness, 
perceived ease of use and usage intention (Chang \& Tung, 2008; Ong et al., 2004). Consistent with research trends and empirical findings in the field of technology adoption, we therefore hypothesise:

H3: An employee's perception of usefulness of e-learning positively influences his/her continuous intention to use e-training solutions in corporations.

H4: An employee's perception of ease of use of e-learning positively influences his/her continuous intention to use e-training solutions in corporations.

\section{Social support theory}

For this study, we define social support as the perceived combined instrumental support, emotional support, and informational support received from different sources, such as family, peers (co-workers), or supervisors. Throughout the years, social support has played an important role in the social psychological literature in predicting the overall well-being of an individual. Research indicates that workplace social support is related to positive vocational outcomes, including reduced absenteeism and position turnover, increased resistance to burnout, and reduced depression and anxiety (Harris, Winskowski, \& Engdahl, 2007). Social support can serve as a form of coping resource. It can help an individual exert situational control through the provision of instrumental aid and advice about how to respond to the situation or handle the problems at hand. Diverting one's attention away from strong stressors, social support can also help an individual to perceive a stressful situation as less threatening. Furthermore, supporters can decrease the distress employees suffer when faced with difficult situations by providing feedback which could be perceived as caring, understanding, or affirmative. Thus, research has found that workplace social support is positively related to greater job satisfaction and training effectiveness, and the level of social support received from significant others, including top management, supervisors, peers, and subordinates, all have an influence on individuals (Chen et al., 2007; Harris et al., 2007). In addition to the social support an employee perceives as having in his/her work environment, Adams, King, and King (1996) uncovered the fact that higher levels of family emotional and instrumental social support are significantly associated with less family and work conflicts, less workplace stress (Noor, 2002), and further believe that a higher level of job satisfaction

(King et al., 1995) would be the result. It is believed that social support from one's family can also positively influence their life at work (Wayne, Randel, \& Stevens, 2006).

Even though most aforementioned studies looked at the relationship between perceived social support and job satisfaction, which is not our main concern, the same analogy can be used to explain the positive relationship between social support from different sources perceived by the employee who participates in the e-learning program and his/her learning satisfaction. Based on our model and previous findings, the following specific hypotheses are proposed concerning the nature of the relationship:

H5: Perceived managerial support is positively related to e-learners' satisfaction.

H6: Perceived peer is positively related to e-learners' satisfaction.

H7: Perceived family support is positively related to e-learners' satisfaction.

Another stem of research regarding the influence of social support is found from the literature on how it serves as an antecedent of employees' motivation to participate in career development. Wang and Wang (2004) proposed a conceptual framework of human resource development (HRD) learning participation, and identified an important factor, organisational social support, affecting learning participation as well as whether the employee will carry through on an HRD learning program. A career-focused learning and development requires a developmental climate that is free of situational constraints such as resource barriers, time problems, and role performance requirements. It also requires the availability of sufficient levels of social support to pursue learning and development opportunities, including psychological support from important others and a positive, supportive development climate of the organisation. Thus, we hypothesise:

H8: Perceived managerial support is positively related to e-learners' continuous intention to adopt e-training.

H9: Perceived peer support is positively related to e-learners’ continuous intention to adopt e-training. 
Continuing on the discussion of the positive influences of family social support (parental and spousal) on an individual e-learner's satisfaction, studies have also revealed its significant role in motivating participation in career development or continued professional education (Harvey, Sinclair, \& Dowson, 2005; Maurer, Weiss, Barbeite, 2003), especially for females (Harrison, 1995; Rudd \& Mackenry, 1986). Therefore, we hypothesise:

H10: Perceived family support is positively related to e-learners’ continuous intention to adopt e-training.

\section{E-learning self efficacy}

When users feel less self-confident about the technology, they also show less positive feelings toward the technology and are less satisfied with it. Therefore, learners’ perceived self-efficacy significantly affects user satisfaction and continued use intention. Thus, the following hypotheses are proposed:

H11: E-learning self-efficacy is positively related to an individual's satisfaction.

H12: E-learning self-efficacy is positively related to an individual's continuous intention to adopt e-training in organisations.

\section{Satisfaction theory}

Satisfaction is the feeling of contentment or disappointment driven from comparing the perceived outcome in relation to expectations, and satisfaction theory is commonly used in the consumer behavioural literatures to understand consumer satisfaction and post-purchase behaviours such as repurchasing and complaining (Anderson \& Sullivan, 1993; Bhattacherjee, 2001). A consumer's level of satisfaction with a product/service determines repurchase intentions, and usually satisfaction is positively correlated with future intentions to repurchase through its impact on attitude. Thus, we build upon this line of argument and hypothesise:

H13: The e-learner's satisfaction positively affects his/her intention to continue to adopt e-training solutions in organisations.

\section{Methodology}

\section{Research participants and data collection}

The data used to test the research model in this study were obtained mainly from a convenience sample of employees in six large corporations in various industries (e.g., telecommunication, banking, insurance) in Taiwan. All the companies involved had implemented some kinds of e-learning modules for their internal training, and each respondent had experience using them. In order to obtain a higher level of return rate, the researchers went to selected organisations several times to administer the questionnaires. Before the survey questionnaire was distributed, the participants were briefed on the purpose of the study and were well informed of their rights to withdraw at anytime during or after the study. The respondents then completed a paper questionnaire, and for each question, were asked to choose the best description of the extent to which they agreed with the statements listed. Overall, each participant took less than 20 minutes to complete the survey.

Of the 700 surveys distributed, 578 valid responses were returned, giving an overall response rate of 82.9\%. This sample size was considered large enough to confirm the measures and examine the research hypotheses using the SEM method. Among these 578 respondents, 335 (58\%) were male, and 243 (42\%) were female; the mean age was 35.08 years $(S D=5.84) ; 82.9 \%$ had a college or university degree, and $13.6 \%$ had completed postgraduate degrees. The vast majority of the participants $(98.7 \%)$ had access to a computer at home, and about 82.3 percent of the participants had 10 or more years of computer usage.

\section{Measurements}

A questionnaire survey consisting of two parts was utilised to test our theoretical model in this study. The first part included demographic questions about the participants, while the second part consisted of 
questions measuring the constructs depicted in the research model. All of the items in the second part were measured by a 5-point Likert-type scale, with answer choices ranging from 1 (strongly disagree) to 5 (strongly agree). Most of these items were adapted from relevant prior studies and the literature, and only minor revisions were made according to the context of the current study.

While the items for perceived usefulness and perceived ease of use were adapted from work by Davis (1989), the items measuring continuous intentions were adapted from work by Bhattacherjee (2001), where both researchers are well known for taking Davis' TAM one step further in considering not just intention to use but also continuous intentions. Moreover, since there is no complete agreement on the definition of e-learning self-efficacy, and researchers tend to have very different perspectives, the e-learning self-efficacy construct here was measured by items modified from Lloyd and Gressard's (1984) instrument, measuring computer self efficacy, and those from Mungania's (2004) study on e-learning self efficacy.

The social support measures described in this study were designed to measure the extent to which an individual perceives that his/her needs for support in finance, information, and emotion are fulfilled by family, peers and supervisors. They were based on Greenhaus and Parasuraman's (1994) definition of social support, and were modified and developed from the inventory in the studies of Procidano and Heller (1983) and Eisenberger, Cummings, Armeli, and Lynch (1997). Finally, the e-learning satisfaction perceived by the individual was measured from items modified from studies by Chiu, Hsu, Sun, Lin, and Sun (2005) and Arbaugh (2000).

In order to gain expert validity, the questionnaire was first drafted and then sent to five academic experts for review. Based on their comments and suggestions, we revised the questionnaire to make the wording of the items more precise. All items used in the questionnaire are listed in Appendix A.

\section{Data analysis and result}

\section{Measurement validation}

The reliability and validity of the measurement model were evaluated using reliability and convergent and discriminant validity criteria in the first step of the data analysis. The reliability of the survey instrument was established by calculating the Cronbach's alpha to measure internal consistency. As shown in Table 1, all of the Cronbach's alpha values were above 0.8 , exceeding the commonly accepted level for explanatory research (Nunnally \& Bernstein, 1994). Following Fornell and Larcker's (1981) suggestion on using multiple indicators to achieve the confidence level to assure a good measurement model, the composite reliability (CR) was computed, and the results are shown in the same table. The composite reliability for each construct in the model ranged from 0.81 to 0.92 , which is higher than 0.7 and was thus considered as evidence of adequate reliability and internal consistency (Nunnally \& Bernstein, 1994).

We also examined the convergent and discriminant validity of the model by using the procedures outlined by Fornell and Larcker (1981). Accordingly, the convergent validity was then evaluated for the measurement scales using two criteria: (1) all indicator factor loadings are significant and exceed 0.70, and (2) the average variance extracted (AVE) for each construct is greater than 0.50 , showing that the variance shared with a construct and its measures exceeds error. As indicated in Table 1, most items revealed a loading higher than 0.7 with a significant level of 0.05 , providing evidence of acceptable item convergence on the intended constructs. Even though two exceptions were found, namely the fifth item of the user satisfaction scale and the third item of the perceived managerial support scale, their loadings were only slightly below 0.7 . Moreover, from Table 2, the AVE ranged from 0.60 to 0.75 greater than variance due to measurement error $(0.5)$; as a result, both conditions for convergent validity were achieved.. 
Table 1

Instrument validity and reliability

\begin{tabular}{|c|c|c|c|c|c|}
\hline Scale & Item & $\begin{array}{c}\text { Factor } \\
\text { loading }\end{array}$ & t-value & CR & Cronbach's $\alpha$ \\
\hline \multirow[t]{7}{*}{ E-learning satisfaction (SA) } & $\mathrm{X} 2$ & .87 & $28.03 *$ & .91 & .93 \\
\hline & X3 & .77 & $22.79 *$ & & \\
\hline & $\mathrm{X} 4$ & .80 & $24.24 *$ & & \\
\hline & X5 & .84 & $25.91 *$ & & \\
\hline & X6 & .64 & $17.18 *$ & & \\
\hline & $\mathrm{X} 7$ & .71 & $20.01 *$ & & \\
\hline & X8 & .78 & $23.19 *$ & & \\
\hline \multirow[t]{2}{*}{ Perceived usefulness (PU) } & $\mathrm{X} 11$ & .85 & $23.35^{*}$ & .81 & .81 \\
\hline & $\mathrm{X} 12$ & .80 & $21.70^{*}$ & & \\
\hline \multirow{5}{*}{ Managerial support (MS) } & $\mathrm{X} 14$ & .76 & $21.06^{*}$ & .90 & .89 \\
\hline & $\mathrm{X} 15$ & .71 & $19.13^{*}$ & & \\
\hline & $\mathrm{X} 17$ & .69 & $18.14^{*}$ & & \\
\hline & $\mathrm{X} 18$ & .91 & $27.79 *$ & & \\
\hline & X19 & .89 & $26.69 *$ & & \\
\hline \multirow[t]{6}{*}{ Peer support (PS) } & X20 & 82 & $23.61^{*}$ & .92 & .92 \\
\hline & $\mathrm{X} 21$ & .87 & $25.93^{*}$ & & \\
\hline & $\mathrm{X} 22$ & .84 & $24.51^{*}$ & & \\
\hline & $\mathrm{X} 23$ & .71 & $19.37 *$ & & \\
\hline & X24 & .87 & $25.93^{*}$ & & \\
\hline & X25 & .80 & $22.64 *$ & & \\
\hline \multirow[t]{5}{*}{ Family support (FS) } & X26 & .80 & $22.94 *$ & .92 & .92 \\
\hline & $\mathrm{X} 27$ & .86 & $25.49 *$ & & \\
\hline & $\mathrm{X} 28$ & .79 & $22.44^{*}$ & & \\
\hline & X29 & .86 & $25.53^{*}$ & & \\
\hline & X30 & .87 & $25.99 *$ & & \\
\hline \multirow{4}{*}{$\begin{array}{l}\text { E-learning self-efficacy } \\
\text { (ELSE) }\end{array}$} & X35 & .73 & $19.52 *$ & .88 & .88 \\
\hline & X36 & .77 & $20.96 *$ & & \\
\hline & X37 & .87 & $25.25 *$ & & \\
\hline & X38 & .83 & $23.27 *$ & & \\
\hline \multirow[t]{2}{*}{ Perceived ease of use (PEOU) } & X39 & .84 & $21.98^{*}$ & .86 & .86 \\
\hline & $\mathrm{X} 40$ & .89 & $23.39 *$ & & \\
\hline \multirow[t]{2}{*}{ Intention (IN) } & $\mathrm{X} 42$ & .88 & $25.41^{*}$ & .85 & .89 \\
\hline & $\mathrm{X} 43$ & .84 & $23.98 *$ & & \\
\hline
\end{tabular}

Note. ${ }^{*} p<0.05$.

For testing discriminant validity, the square root of the AVE from the construct should be greater than the correlation shared between the construct and other constructs in the model (Fornell \& Larcker, 1981). Table 2 shows the correlations among the constructs, with the square root of the AVE on the diagonal. According to the criteria, diagonal elements should be larger than off-diagonal elements. Since all of the diagonal values exceeded their inter-construct correlations, the test of discriminant validity was also acceptable. Therefore it was concluded that, overall, the measurement model results provide support for the reliability and convergent and discriminant validities of the measures used in the study. 
Table 2

Correlations of latent variables and AVE

\begin{tabular}{cccccccccc}
\hline \multirow{2}{*}{ Construct } & \multicolumn{10}{c}{ AVE and squared correlations } \\
& AVE & SA & PU & MS & PS & FS & ELSE & PEOU & IN \\
\hline SA & .60 & .77 & & & & & & & \\
PU & .68 & $.657 * *$ & .82 & & & & & & \\
MS & .63 & $.523^{* *}$ & $.457^{* *}$ & .79 & & & & & \\
PS & .67 & $.573^{* *}$ & $.499^{* *}$ & $.706^{* *}$ & .82 & & & \\
FS & .70 & $.537^{* *}$ & $.469^{* *}$ & $.571^{* *}$ & $.680^{* *}$ & .84 & & \\
ELSE & .64 & $.510^{* *}$ & $.458^{* *}$ & $.273^{* *}$ & $.268^{* *}$ & $.314^{* *}$ &. $\mathbf{8 0}$ & & \\
PEOU & .75 & $.618^{* *}$ & $.597^{* *}$ & $.422^{* *}$ & $.487^{* *}$ & $.497^{* *}$ & $.435^{* *}$ & .87 & \\
IN & .74 & $.568^{* *}$ & $.548^{* *}$ & $.357^{* *}$ & $.397^{* *}$ & $.395^{* *}$ & $.631^{* *}$ & $.596^{* *}$ & $\mathbf{. 8 6}$ \\
\hline
\end{tabular}

Note. Diagonal elements (in bold) represent the square root of the average variance extracted (AVE). Off-diagonal elements represent the correlations among constructs.

$* * * p<0.001, * * p<0.01, * p<0.05$

\section{Test of the research model}

In the second phase of the data analysis, the overall fit and the explanatory power of the structure model were assessed using LISREL 8.50 to confirm to what extent the relationships specified by the proposed model are consistent with the data collected. First, the overall structure model was assessed based on the following standards of goodness of model fit provided by Hu and Bentler (1999): chi-square $\left(\chi^{2}\right)$ statistic, the comparative fit index (CFI), the root-mean-square error of approximation (RMSEA), the standardised root-mean-square residual (SRMR), the non-normed fit index (NNFI), and $\chi 2 /$ degree of freedom $\left(\chi^{2} / \mathrm{df}\right)$. Table 3 summarises the results of the analysis, showing that all of the indices exceeded their respective common acceptance levels (Hu \& Bentler, 1999; Kelloway, 1998), suggesting that the research model provided a good fit to the data. The chi-square value was 2020.63 with 532 degrees of freedom ( $\chi 2 / \mathrm{df}$ was 4.08), NNFI was 0.97, CFI was 0.98, RMSEA was 0.072, and SRMR was 0.045.

Table 3

Summary statistics of model fit

\begin{tabular}{lcc}
\hline Model goodness-fit indexes & Results in this study & Recommended value \\
\hline Chi-square/degree of freedom & 4.08 & Between 2 and 5 \\
Non-normed fit index (NNFI) & 0.97 & $\geq .90$ \\
Comparative fit index (CFI) & 0.98 & $\geq .95$ \\
Standardised root-mean-square residual (SRMR) & 0.045 & $\leq .06$ \\
Root-mean-square error of approximation (RMSEA) & 0.072 & $\leq .10$ \\
\hline
\end{tabular}

Hypothesis testing was performed by examining the size, the sign, and the significance of the path coefficients, respectively. The significant standardised path coefficients for the research model are presented in Figure 2. With a 0.05 significance level, it was found that most of the paths were significant in the expected direction, and the only exceptions were paths drawn from managerial support, peer support, and e-learning self-efficacy to continuous usage intention, and from family support to user satisfaction. Therefore, the results provide support for most of the hypotheses, except for H7, H8, H9, and H12. Thus, in contrast with our predictions, direct positive significant relationships of managerial support, peer support, and e-learning self-efficacy with continuous usage intention, and direct positive significant relationship of family support with user satisfaction could not be found in this study. The significant path coefficients from perceived usefulness, perceived ease of use, managerial support, peer support, and e-learning self-efficacy to user satisfaction were $0.43,0.19,0.1,0.12,0.12$ respectively; from perceived usefulness, perceived ease of use, and family support to continuous usage intention, they were $0.35,0.12$, and 0.14 respectively; and from user satisfaction to continuous usage intention, it was 0.22 . The magnitude and significance of these path coefficients provide further evidence in support of the validity of the research model.

Another indicator of the predictive and explanatory power of path models is to examine the explained variance or $\mathrm{R}^{2}$ values, which are also exhibited in Figure 2. The results indicate that perceived usefulness, 
perceived ease of use, managerial support, peer support, and e-learning self-efficacy account for $66 \%$ of the variance in the user satisfaction construct, while perceived usefulness, perceived ease of use, family support, and user satisfaction account for $56 \%$ of variance in the continuous usage intention construct. The percentage of variance explained for these primary dependent variables was greater than $50 \%$, implying the satisfactory and substantive value and predictive power of the model.

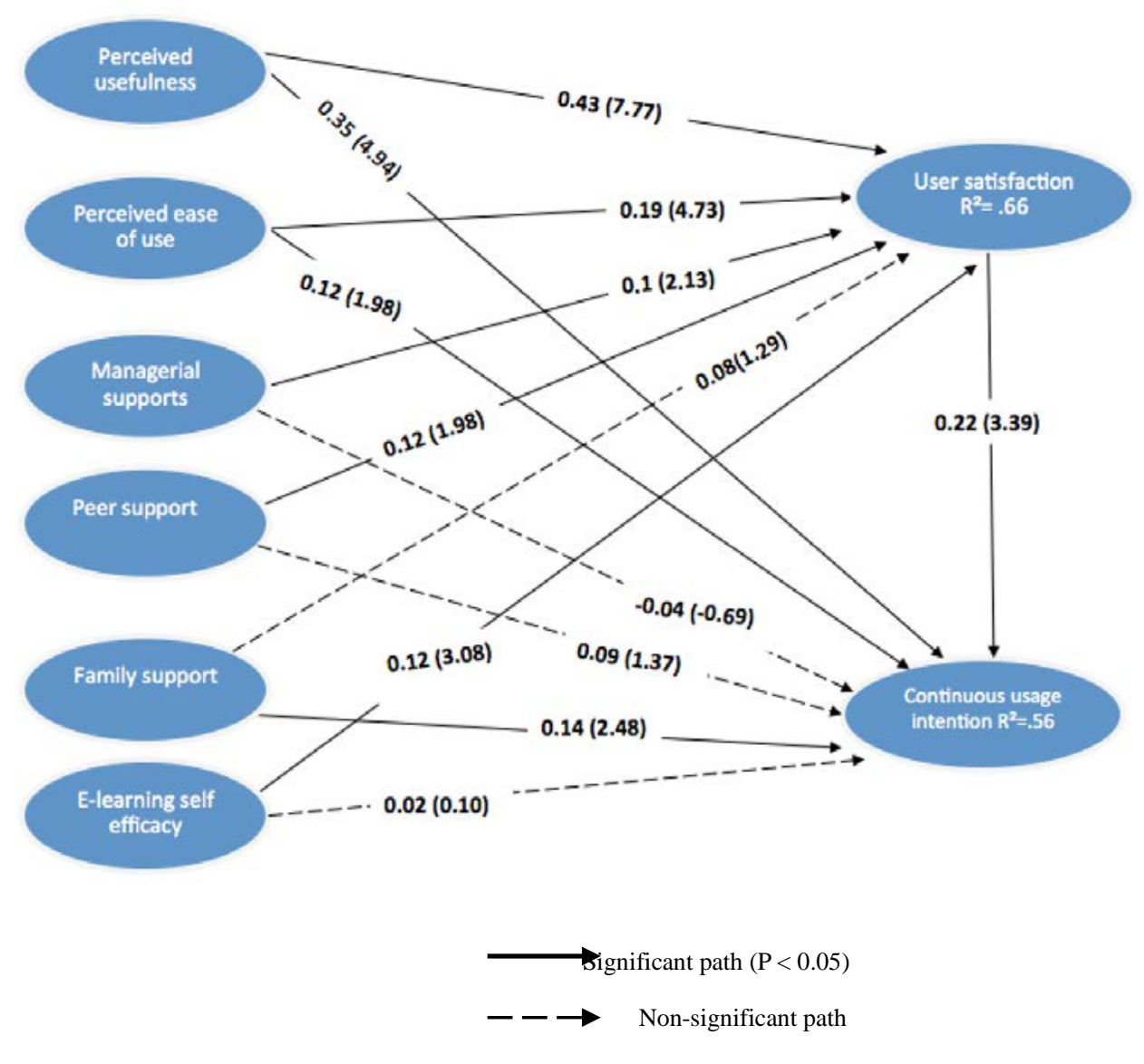

Path coefficients are reported with t-values in brackets

Figure 2. Summary of the research model with significant relationships

\section{Discussion}

The goal of the present study was to extend the TAM for e-learning's continuous usage in corporations by including variables of social support from different sources, e-learning self-efficacy, and user satisfaction as direct antecedents of continuous usage intention. We also examined the results of these social support variables, perceived usefulness, perceived ease of use, and e-learning self-efficacy on user satisfaction. Based on the aforementioned results, we believe that the present study provides a good explanation of users' satisfaction as well as their continuous usage intention with regards to e-training services. Furthermore, it also provides strong empirical support for most of our proposed hypotheses, and helps clarify the vital roles those antecedents play in e-learner satisfaction and decisions regarding the continuous use formation process. In this study, the constructs formulated explain a higher proportion of the variance of behavioural intentions than the original TAM in Davis' (1989) study. This reveals that integrating the theoretical constructs of the TAM with others can definitely increase the power to predict and explain e-learners' future behavioural intentions. 
As expected, perceived usefulness was found to be the strongest determinant of both user satisfaction and continuous usage intention, and its effect strength was much higher than the effects any other significant determinants had on dependent variables. This suggests that a learner's belief in e-learning usefulness is a primary decisive variable of his/her perception of satisfaction and intentions for future use. The results are consistent with previous research which discovered that perceived usefulness plays a more significant and stronger role than perceived ease of use (Davis, Bagozzi, \& Warshaw, 1989), which is the second strongest determinant found for learner's satisfaction, and the fourth strongest for the intention of future use in our study. According to Eccles and Wigfield (1995), value beliefs tend to be better predictors of both satisfaction and choice behaviours than expectancy beliefs (e.g., self-efficacy), especially for adults. In other words, when trainees consider that the e-learning service could provide useful and relevant information for their jobs, they are more interested in using it, and this increases their satisfaction as well as their intentions to use it again in the future. It also implies that an understanding of what value means to users offers the promise of establishing long-term user relationships. Since perceived usefulness is the most important predictor of continuous intention, administrators can increase users' usage intention by improving their beliefs of how the e-learning system can enhance their job performance and effectiveness. Therefore, providing useful services that can improve job performance and gain organisational rewards is the first consideration in promoting a user's continuous intention.

Furthermore, this study also found the direct influences of perceived social support from managers and peers on user satisfaction to be significant, whereas family support does not have a significant effect. A possible explanation could be that a user's satisfaction with the e-learning solution is only affected by the immediate social environment of his/her work, but not by the family. This finding is congruent with Chen et al.'s (2007) study of organisational training in a traditional learning environment, indicating that teamwork and management support, such as positive feedback, shared ideas, promotion, and opportunities to practise the skills learned, all enable training to be effective. Given that management support is positively correlated with user satisfaction, researchers have also discussed the fact that social support for e-learning in the work context is essential, not just to obtain personnel and monetary resources, but also to mitigate one's negative attitude towards the technology and overcome user resistance (Lee \& Kim, 2009). Thus, even though in the current study perceived social support from managers and peers does not have a significant direct impact on learners' behavioural choices regarding the future, both types of support are important antecedents of e-learning outcomes (i.e., learning satisfaction).

E-learning self-efficacy was found to be another important factor influencing user satisfaction, but, inconsistent with our hypotheses, it has no significant direct effect on continuous usage intention. Even though self-efficacy has been proved to play an important role in user motivation (Chang \& Tung, 2008), it does not have a direct impact, but rather needs to be mediated by user satisfaction; therefore, the findings indicate that the focus of training programs should also be on building the confidence level of user experience. Training in basic skills of using e-learning programs, thus enhancing confidence, should not be ignored, for it will lead to more effective use of the training systems and add to the overall learner satisfaction. Moreover, learner satisfaction affects the continuous usage intention, and mediates the effect of perceived managerial and peer social support, perceived ease of use and usefulness, and e-learning self-efficacy. The result supports the user satisfaction theory and is congruent with Bhattacherjee, Perols, and Sandford's (2008) study, which demonstrated that user satisfaction is an important mediator for all of these aforementioned determinants. Thus, strategies to maximise users' satisfaction are also considered as important in the process of implementing successful e-learning programs.

Finally, one of the most important findings in this study is the significant, direct positive impact of perceived family support on the continuous intention of e-learning. It is believed that the more social support from family perceived by the employee during the e-training, the higher possibility there is that he/she will want to continue utilising the e-training opportunity in the future. This important determinant was neglected in prior studies associated with factors affecting e-learning continuous intention; however, this study indicates that it also plays a vital role in the process of forming a behavioural decision. The result is consistent with previous findings (Carlson \& Perrewe, 1999) on how family social support is considered to be beneficial in helping people balance time commitments and role constraints as well as reducing work-family conflicts. As learning or training media have become digitalised and web-based, more people have expressed their concerns about the lack of time to participate. They raise the issue of limited time resources for attending e-learning during work hours, and the possibility of creating a 
work-family conflict (Borotis \& Poulymenakou, 2009). Perhaps, learners have different conceptions of web-based learning, and these conceptions, guiding their beliefs about the experience of learning as well as their interpretations of learning itself, are related to their learning approaches and outcomes (Tsai, 2009). Instead of considering training as a form of benefit which companies have provided to employees in the past (Acton \& Golden, 2001), currently employees see it as extra work they have to do in their own time. As a result, when learners believe that they have extra resources (family supports) from home to utilise, they will be more likely to participate in the e-learning programs which might advance their job performance or human capital in the future. This implies that instead of just searching for the benefits of new media, we also need to consider how to overcome the unintended problems that might be brought about when implementing this new form of training.

\section{Limitations and implications for future studies}

Despite its many important findings, the present study also suffers from several limitations which can be identified to help drive future research. First, since our findings and implications are obtained from samples comprising the employees of several corporations in Taiwan, caution needs to be taken when generalising our results to different contexts. The subjects in this study were primarily employees who have participated in e-learning or e-training programs. Their continuance decisions and satisfaction may be different from those of students who are enrolled in other kinds of e-learning programs run in traditional learning institutes. Future research is necessary to examine whether the effects of the identified endogenous variables in our model would vary according to context. Secondly, this study represents a snapshot at a particular point in time, so additional research efforts are also required to determine the validity of the proposed model and our findings. Further longitudinal studies are thus recommended to validate our research model in this regard. Finally, the R-square reported by the current research indicates that there may be a need to search for additional variables (e.g., subjective norm, gender, computing experience, education background) to improve our ability to predict continuous usage intentions more thoroughly.

\section{Conclusion}

To conclude, the results from this study reveal that usefulness, ease of use, social support, and self-efficacy are considered important issues in e-learning participation in organisations; some of the factors can affect the decisions directly, while others are mediated by learner satisfaction. Using the extended model as a theoretical framework, the present study helps practitioners and researchers better understand why people continue to use e-learning, predict how they will respond to e-learning, and increase their acceptance by improving the strategies and processes by which they are implemented. Moreover, it also helps researchers consider our findings for future development and evaluation of e-learning theories.

\section{Acknowledgements}

This work was supported by the National Science Council (NSC), Taiwan, ROC, under Contracts No. NSC96-2511-S-011-002-MY3 and NSC 101-2511-S-011-004.

\section{References}

Acton, T., \& Golden, W. (2001). Training: The way to retain valuable IT employees? In E. Cohen (Ed.), Proceedings of the Information Science and Information Technology Education Conference (pp. 1-12). Cork: University College Cork.

Adams, G. A., King, L. A., \& King, D. W. (1996). Relationships of job and family involvement, family social support, and work-family conflict with job and life satisfaction. Journal of Applied Psychology, 81(4), 411-420. http://dx.doi.org/10.1037/0021-9010.81.4.411

Anderson, E. W., \& Sullivan, M. W. (1993). The antecedents and consequences of customer satisfaction for firms. Marketing Science, 12(2), 125-143. http://dx.doi.org/10.1287/mksc.12.2.125

Arbaugh, J. B. (2000). Virtual classroom characteristics and student satisfaction in internet-based MBA courses. Journal of Management Education, 24(1), 32-54. 
http://dx.doi.org/10.1177/105256290002400104

Ball, K., Jeffery, R.W., Abbot, G., McNaughton, S.A., \& Crawford, D. (2010). Is healthy behavior contagious: associations of social norms with physical activity and healthy eating, International Journal of Behavioral Nutrition and Physical Activity, 7(86). http://dx.doi/10.1186/1479-5868-7-86

Bandura, A. (1986). Social foundations of thought and action. Englewood Cliffs, NJ: Prentice-Hall.

Bhattacherjee, A. (2001). Understanding information systems continuance: An expectation-confirmation model. MIS Quarterly, 25(3), 351-370. http://dx.doi.org/10.2307/3250921

Bhattacherjee, A., Perols, J., \& Sanford, C. (2008). Information technology continuance: A theoretical extension and empirical test. Journal of Computer Information Systems, 49(1), 17-26. Retrieved from http://www.iacis.org/jcis/jcis toc.php?volume=49\&issue $=1$

Borotis, S., \& Poulymenakou, A. (2009). E-learning acceptance in workplace training: The case of a Greek bank. In S. Newell, E. A. Whitley, N. Pouloudi, J. Wareham, \& L. Mathiassen (Eds.), Proceedings of the 17th European Conference on Information Systems (pp. 1500-1512). Verona: University of Verona. Retrieved from http://is2.lse.ac.uk/asp/aspecis/20090124.pdf

Carlson, D. S., \& Perrewe, P. L. (1999) The role of social support in the stressor-strain relationship: An examination of work-family conflict. Journal of Management, 25(4), 513-540. http://dx.doi.org/10.1177/014920639902500403

Chang, S.-C., \& Tung, F.-C. (2008). An empirical investigation of students' behavioral intentions to use the online learning course websites. British Journal of Educational Technology, 39(1), 71-83.

Chen, C.-Y., Sok, P., \& Sok, K. (2007). Exploring potential factors leading to effective training: An exclusive study on commercial banks in Cambodia. Journal of Management Development, 26(9), 843-856. http://dx.doi.org/10.1108/02621710710819339

Chen, E. T. (2008). Successful e-learning in corporations. Communications of the IIMA, 8(2), 45-54.

Chiu, C.-M., Hsu, M.-H., Sun, S.-Y., Lin, T.-C., \& Sun, P.-C. (2005). Usability, quality, value, and e-learning continuance decisions. Computers \& Education, 45(4), 399-416. http://dx.doi.org/10.1016/j.compedu.2004.06.001

Chiu, C.-M., Sun, S.-Y., Sun, P.-C., \& Ju, T. J. (2007). An empirical analysis of the antecedents of web-based learning continuance. Computers \& Education, 49(4), 1224-1245. http://dx.doi.org/10.1016/j.compedu.2006.01.010

Chuo, Y. H., Tsai, C. H., Lan, Y. L., \& Tsai, C. S. (2011). The effect of organizational support, self efficacy and computer anxiety on the usage intention of e-learning system in hospital. African Journal of Business Management, 5(14), 5518-5523.

Courneya, K. S., \& McAuley, E. (1995). Cognitive mediators of the social influence - exercise adherence relationship: A test of the theory of planned behavior. Journal of Behavioral Medicine, 18(5), 499-515. http://dx.doi.org/10.1007/BF01904776

Davis, F., Bagozzi, R. P., \& Warshaw, P. R. (1989). User acceptance of computer technology: A comparison of two theoretical models. Management Science, 35(8), 982-1003. http://dx.doi.org/10.1287/mnsc.35.8.982

Davis, F. D. (1989). Perceived usefulness, perceived ease of use, and user acceptance of information technology. MIS Quarterly, 13, 319-340. http://dx.doi.org/10.2307/249008

Eccles, J. S., \& Wigfield, A. (1995). In the mind of the actor: The structure of adolescents' achievement task values and expectancy-related beliefs. Personality and Social Psychology Bulletin, 21(3), 215-225. http://dx.doi.org/10.1177/0146167295213003

Eisenberger, R., Cummings, J., Armeli, S., \& Lynch, P. (1997). Perceived organizational support, discretionary treatment, and job satisfaction. Journal of Applied Psychology, 82(5), 812-820. http://dx.doi.org/10.1037/0021-9010.82.5.812

Felman-Baruch, C., \& Schwartz, J. (2002). Sources of social support and burnout, job satisfaction, and productivity. Journal of Occupational Health Psychology, 7(1), 84-93.

Fishbein, M., and Ajzen, I. (1975). Belief attitude intention, and behavior: an introduction to theory and research, Reading, MA: Addison-Wesley.

Fornell, C., \& Larcker, D. (1981). Evaluating structural equation models with unobservable variables and measurement error. Journal of Marketing Research, 18(1), 39-50. http://dx.doi.org/10.2307/3151312

Greenhaus, J. H., \& Parasuraman, S. (1994). Work-family conflict, social support, and well-being. In M. J. Davidson \& R. J. Burke (Eds.), Women in management: Current research issues (pp. 213-229). London: Paul Chapman.

Harris, J. I., Winskowski, A. M., \& Engdahl, B. E. (2007). The types of workplace social support in the prediction of job satisfaction. The Career Development Quarterly, 56(2), 150-156. 
http://dx.doi.org/10.1002/j.2161-0045.2007.tb00027.x

Harrison, M. E. (1995). A doctor's place: female physicians in Mexico DF. Health \& Place, 1(2), 101-111. http://dx.doi.org/10.1016/1353-8292(95)00013-C

Harvey, P., Sinclair, C., \& Dowson, M. (2005). Teacher motivations for postgraduate study: Development of a psychometric scale for Christian higher education. Christian Higher Education Journal, 4(4), 241-264. http://dx.doi.org/10.1080/15363750500182588

House, J. S. (1981). Work stress and social support. Reading, MA: Addision-Wesley.

Hsu, M.-H., Yen, C.-H., Chiu, C.-M., \& Chang, C.-M. (2006). A longitudinal investigation of continued online shopping behavior: An extension of the theory of planned behavior. International Journal of Human-Computer Studies, 64(9), 889-904. http://dx.doi.org/10.1016/j.ijhcs.2006.04.004

Hsu, Y. C., Ho, S. N., Tsai, C.-C., Hwang, G. J., Chu, H. C., \& Wang, C. Y. (2012). Research trends in technology-based learning from 2000 to 2009: A content analysis of publications in selected journals. Educational Technology \& Society, 15(2), 354-370.

Hu, L., \& Bentler, P. M. (1999). Cutoff criteria for fit indexes in covariance structure analysis: Conventional criteria versus new alternatives. Structural Equation Modeling, 6(1), 1-55. http://dx.doi.org/10.1080/10705519909540118

Joo, Y. J., Bong, M., \& Choi, H. J. (2000). Self-efficacy for self-regulated learning, academic self-efficacy, and Internet self-efficacy in Web-based instruction. Educational Technology Research and Development, 48(2), 5-17. http://dx.doi.org/10.1007/BF02313398

Kelloway, E. K. (1998). Using LISREL for structural equation modeling: A researcher's guide. Thousand Oaks, CA: Sage.

King, L. A., Mattimore, L. K., King, D. W., \& Adams, G. A. (1995). Family support inventory for workers: A new measure of perceived social support from family members. Journal of Organizational Behavior, 16(3), 235-258. http://dx.doi.org/10.1002/job.4030160306

Kranz, G. (2008). E-learning hits its stride. Workforce Management. Retrieved from http://www.workforce.com/articles/e-learning-hits-its-stride

Lee, S., \& Kim, B. G. (2009). Factors affecting the usage of intranet: A confirmatory study. Computers in Human Behavior, 25(1), 191-201. http://dx.doi.org/10.1016/j.chb.2008.08.007

Levitt, B., \& March, J. G. (1988). Organizational learning. Annual Review of Sociology, 14, 319-340.

Loyd, B. H., \& Gressard, C. P. (1984). Reliability and factorial validity of computer attitude scale. Educational and Psychological Measurement, 44(2), 501-505. http://dx.doi.org/10.1177/0013164484442033

Lu, J., Yu, C.-S., Liu, C., \& Yao, J. E. (2003). Technology acceptance model for wireless Internet. Internet Research, 13(3), 206-222.

Mathieson, K. (1991). Predicting user intentions: Comparing the technology acceptance model with the theory of planned behavior. Information Systems Research, 2(3), 192-222. http://dx.doi.org/10.1287/isre.2.3.173

Maurer, T., Weiss, E., \& Barbeite, F. (2003). A model of involvement in work-related learning and development activity: The effects of individual, situational motivational, and age variables. Journal of Applied Psychology, 88(4), 707-24. http://dx.doi.org/10.1037/0021-9010.88.4.707

Miller, L. (2012). ASTD 2012 State of the industry report: Organizations continue to invest in workplace learning. Retrieved from http://www.astd.org/Publications/Magazines/TD/TD-Archive/2012/11/ASTD-2012-State-of-the-Indus try-Report

Mungania, P. (2004). Employees' perceptions of e-learning barriers: The relationship among barriers, demographics, and e-learning self-efficacy (Doctoral dissertation). University of Louisville, Lousville. Retrieved from http://digital.library.louisville.edu/cdm/singleitem/collection/etd/id/500

Noor, N. M. (2002). The moderating effect of spouse support on the relationship between work variables and women's work-family conflict. Psychologia, 45(1), 12-23. http://dx.doi.org/10.2117/psysoc.2002.12

Nunnally, J. C., \& Bernstein, I. H. (1994). Psychometric theory (3rd ed.). New York, NY: McGraw-Hill.

Ong, C.-S., Lai, J.-Y., \& Wang, Y.-S. (2004). Factors affecting engineers' acceptance of asynchronous e-learning systems in high-tech companies. Information \& Management, 41(6), 795-804. http://dx.doi.org/10.1016/j.im.2003.08.012

Procidano, M. E., \& Heller, K. (1983). Measures of perceived social support from friends and from family: Three validation studies. American Journal of Community Psychology, 11(1), 1-24. http://dx.doi.org/10.1007/BF00898416 
Raaij, E. M. van, \& Schepers, J. J. L. (2008). The acceptance and use of a virtual learning environment in China. Computers and Education, 50(3), 838-852. http://dx.doi.org/10.1016/j.compedu.2006.09.001

Roca, J. C., Chiu, C.-M., \& Martinez, F. J. (2006). Understanding e-learning continuance intention: An extension of the Technology Acceptance Model. International Journal of Human-Computer Studies, 64(8), 683-696. http://dx.doi.org/10.1016/j.ijhcs.2006.01.003

Rudd, N. M., \& Mckenry, P.C. (1986). Family influences on the job satisfaction of employed mothers. Psychology of Woman Quarterly, 10(4), 363-372. http://dx.doi.org/10.1111/j.1471-6402.1986.tb00761.x

Schepers, J., \& Wetzels, M. (2007). A meta-analysis of the technology acceptance model: Investigating subjective norm and moderation effects, Information and Management, 44(1), 90-103. http://dx.doi.org/10.1016/j.im.2006.10.007

Shumaker, S. A., \& Brownell, A. (1984). Toward a theory of social support: Closing conceptual gaps. Journal of Social Issues, 40(4), 11-36. http://dx.doi.org/10.1111/j.1540-4560.1984.tb01105.X

Sun, P.-C., Tsai, R. J., Finger, G., Chen, Y.-Y., \& Yeh, D. (2008). What drives a successful e-Learning? An empirical investigation of the critical factors influencing learner satisfaction. Computers \& Education, 50(4), 1183-1202. http://dx.doi.org/10.1016/j.compedu.2006.11.007

Tsai, C.-C. (2009). Conceptions of learning versus conceptions of web-based learning: The differences revealed by college students. Computers \& Education, 53(4), 1092-1103. http://dx.doi.org/10.1016/j.compedu.2009.05.019

van Veldhoven, M., de Jonge, J., Broersen, S., Kompier, M., \& Meijman, T. (2002). Specific relationships between psychosocial job conditions and job-related stress: A three-level analytic approach. Work \& Stress, 16(3), 207-228.

Venkatesh V., \& Davis F. D. (2000) A theoretical extension of the technology acceptance model: four longitudinal field studies. Management Science, 46(2), 186-204. http://dx.doi.org/10.1287/mnsc.46.2.186.11926

Wang, G., \& Wang, J. (2004). Toward a theory of HRD participation. Human Resource Development Review, 3(4), 326-353. http://dx.doi.org/10.1177/1534484304271152

Wang, M., Ran, W., Liao, J., \& Yang, S. J. H. (2010). A performance-oriented approach to e-learning in the workplace. Educational Technology \& Society, 13(4), 167-179.

Way, M., \& MacNeil, M. (2006). Organizational characteristics and their effect on health. Nursing Economics, 24(2), 67-77.

Wayne, J. H., Randel, A. E., \& Stevens, J. (2006). The role of identity and work-family support in work-family enrichment and its work-related consequences, Journal of Vocational Behavior, 69(3), 445-461. http://dx.doi.org/10.1016/j.jvb.2006.07.002

Zakaria, N. (2000). The effects of cross-cultural training on the acculturation process of the global workforce. International Journal of Manpower, 21(6), 492-511. http://dx.doi.org/10.1108/01437720010377837

Corresponding author: Cathy Weng, cathyhaien@hotmail.com

Australasian Journal of Educational Technology (C) 2015.

Please cite as: Weng, C., Tsai, C-C. \& Weng, A. (2015). Social support as a neglected e-learning motivator affecting trainee's decisions of continuous intentions of usage. Australasian Journal of Educational Technology, 31(2), 177-192. 
Appendix A

Items used to measure research constructs

\begin{tabular}{lll}
\hline Constructs & Variables & Items \\
(SA) & (SA1) & I am satisfied with the way my e-learning is presented. \\
& (SA2) & I am satisfied with the fact that e-learning will be able to provide multiple \\
& learning channels. \\
& (SA4) & I am satisfied with the interactivity of the e-learning course. \\
& Overall, I am satisfied with the e-learning environment. \\
& (SA6) & Overall, I am satisfied with the sociability of the e-learning service. \\
& I am satisfied with the learning effect and various evaluation methods \\
& (SAf) & Overed by the e-learning solution. \\
\hline Perceived & (PU1) & Using the e-learning service can improve my learning performance. \\
usefulness & (PU2) & I find the e-learning service to be useful to me.
\end{tabular}

(PU)

$\begin{array}{lll}\text { Managerial } & \text { (MS1) } & \text { When I encounter difficulties during e-learning, my supervisors are willing } \\ \text { support (MS) } & & \text { to listen and provide the emotional support I need. } \\ & \text { (MS2) } & \text { My supervisors always encourage and support the use of the e-learning }\end{array}$

(MS2) My supervisors always encourage and support the use of the e-learning service.

(MS3) When I have great performance in e-learning, my supervisors will provide monetary rewards or opportunities for promotion.

(MS4) When I face problems during e-learning, my supervisors will give me support, help me analyze problems, and make decisions on ways to solve the problem.

(MS5) When I am using the e-learning service, my supervisors will provide the relevant information and help me improve my performance.

\begin{tabular}{lll}
\hline $\begin{array}{l}\text { Peer support } \\
\text { (PS) }\end{array}$ & (PS1) & $\begin{array}{l}\text { When I am using the e-learning service, my peers will encourage and } \\
\text { praise me. }\end{array}$ \\
& (PS2) & When I face problems during e-learning, my peers will listen and provide
\end{tabular}

(PS2) When I face problems during e-learning, my peers will listen and provide the emotional support I need.

(PS3) My peers would encourage me to use the e-learning services.

(PS4) While using the e-learning services, if there are problems with the computer or system, my peers will come to help right away.

(PS5) When I face problems during e-learning, peers will provide support for analyzing the problems and help find the best solution to resolve it.

(PS6) When I use the e-learning services, peers will provide informational advice and guidance.

Family
support (FS)

(FS1) When I am using the e-learning service, my family will encourage and praise me.

(FS2) When I face problems during e-learning, my family will listen and provide the affection I need.

(FS3) When I use the e-learning service, my family will voluntarily take over my share of work.

(FS4) When I use the e-learning service, my family will help me collect the necessary information I need.

(FS5) When I use the e-learning service, my family will share with me their experience of e-learning and any other important things we need to know.

\begin{tabular}{lll}
\hline $\begin{array}{l}\text { E-learning } \\
\text { self-efficacy } \\
\text { (ELSE) }\end{array}$ & $\begin{array}{l}\text { (ELSE1) } \\
\text { (ELSE2) }\end{array}$ & $\begin{array}{l}\text { I am confident in my abilities to make use of computers and the Internet in } \\
\text { learning (to learn with e-learning). }\end{array}$ \\
& $\begin{array}{l}\text { I aLSE3) } \\
\text { (ELSE4) }\end{array}$ & $\begin{array}{l}\text { I am sure that I have great learning performance via the e-learning service. } \\
\text { When I use e-learning services, I feel confident. }\end{array}$ \\
\hline $\begin{array}{l}\text { Perceived ease } \\
\text { of use (PEOU) }\end{array}$ & (PEOU1) & Learning to operate the e-learning applications is easy for me. \\
\hline Intention (IN) & (IN1) & It is easy for me to become skillful at using the e-learning applications. \\
& (IN2) & I will strongly recommend others to use e-learning solutions.
\end{tabular}

